Reports

\title{
Am I doing better than you? That depends on whether you ask me in English or Chinese: Self-enhancement effects of language as a cultural mindset prime
}

\author{
Spike W.S. Lee ${ }^{\mathrm{a}, *}$, Daphna Oyserman ${ }^{\mathrm{a}, * *}$, Michael Harris Bond ${ }^{\mathrm{b}}$ \\ a Department of Psychology, University of Michigan, East Hall, 530 Church Street, Ann Arbor, MI 48109-1043, United States \\ ${ }^{\mathrm{b}}$ Department of Applied Social Sciences, Hong Kong Polytechnic University, Hung Hom, Kowloon, Hong Kong
}

\section{A R T I C L E I N F O}

\section{Article history:}

Received 5 November 2009

Revised 24 February 2010

Available online 18 April 2010

\section{Keywords:}

Priming

Language

Self-esteem

Social cognition

\begin{abstract}
A B S T R A C T
Westerners tend to judge themselves positively unless their failure relative to others is obvious, in which case they tend to distance themselves from outperforming others. Whether this tendency to self-enhance in social-comparison situations is universal or culture-bound is hotly debated. Rather than construe selfenhancement as either universal or culture-bound, we propose that its effects depend on the cultural mindset that is salient at the moment of self-reflection. A cultural mindset is a mental representation containing culture-congruent content, procedures, and goals. We focused on individual and collective mindsets, using language as an unobtrusive mindset prime and predicting that people would be more self-enhancing when an individual mindset was made salient by using English than when a collective mindset was made salient by using Chinese. Three studies supported this hypothesis. Chinese students self-enhanced (rating themselves as better than others and distancing themselves from outperforming others) more when primed with an individual mindset.
\end{abstract}

(c) 2010 Elsevier Inc. All rights reserved.

\section{Introduction}

"It was an important final exam. Very difficult. . . I really wanted to take a look at her answers.... I fought with my evil spirit. At last, I succeeded." (Chinese college student, male, 19, recalling a moment of moral struggle in elementary school)

Everyday moral struggles are common. Sometimes people succeed, other times they fail, in spite of their best efforts and others' success. We are interested in how people judge themselves in these success and failure situations. A large literature suggests that the most common response, at least among North Americans and Western Europeans, is to self-enhance, that is, to judge one's strengths as unique and to put distance between oneself and outperforming others when one's own failure cannot be denied (Leary, 2007). Indeed, some cultural psychologists view self-enhancement as so pronounced in the West as to constitute a distinct phenomenon central to individualistic societies (Heine \& Hamamura, 2007; Heine, Kitayama, \& Hamamura, 2007a, 2007b). Others counter that self-enhancement is a universal motive with cultures differing in

\footnotetext{
* Correspondence to: Spike W.S. Lee, Department of Psychology, University of Michigan, 3221 East Hall, 530 Church Street, Ann Arbor, MI 48109-1043, USA.

** Correspondence to: Daphna Oyserman, Institute for Social Research, 426 Thompson, Ann Arbor, MI 48109-1248, USA.

E-mail addresses: spikelee@umich.edu (S.W.S. Lee), daphna.oyserman@umich. edu (D. Oyserman).
}

their tactics to achieve it-some self-enhancing on individualistic attributes, others on collectivistic ones (Sedikides, Gaertner, \& Toguchi, 2003; Sedikides, Gaertner, \& Vevea, 2005, 2007a, 2007b). We propose a reframing of the argument: Rather than being fixed parts of either a particular culture or of human nature, the quality and quantity of self-enhancing responses are dependent on which cultural mindset is salient at the moment of selfreflection. Three studies unobtrusively manipulate language use to prime cultural mindsets and provide evidence that selfenhancement occurs even in collectivistic societies when an individual mindset is primed, showing effects on a variety of tasks.

\section{Cultural mindsets}

A cultural mindset is a mental representation or cognitive schema containing culture-congruent content, procedures, and goals (Oyserman \& Lee, 2008a; Oyserman, Sorensen, Reber, \& Chen, 2009). Cultural psychologists have distinguished individualism from collectivism (e.g., Hofstede, 1980; Kim, Triandis, Kagitcibasi, Choi, \& Yoon, 1994; Markus \& Kitayama, 1991; Triandis, 1995), and countries can be distinguished on these axes (Oyserman, Coon, \& Kemmelmeier, 2002). This implies that core cultural mindsets differentiate individualistic and collectivistic cultural perspectives. Specifically, an individual mindset involves content (being positive about the self, standing out), procedures (contrasting, separating), and goals (striving for individual success) that differ from those of 
a collective mindset (being modest about the self, fitting in; assimilating, connecting; striving for relational harmony, collective wellbeing).

To understand how cultural mindsets matter for self-enhancement, we focus on traits and domains in which people would likely prefer success to failure. We propose that cultural mindsets shift the meaning attributed to one's successes and failures and therefore which behaviors are likely when one fails (despite one's best efforts) in the face of others' success. Within an individual mindset, salient self-uniqueness content, self-positivity goals and contrasting procedures together support a sense of one's distinctive success relative to others (e.g., "I am uniquely able to avoid this temptation; many of my peers would have cheated"). When failure cannot be mitigated by claiming that it is common ("it's not just me; everybody did that"), uniqueness content coupled with a positivity goal and a contrasting procedure would facilitate distancing from others to reduce the salience of failure.

Conversely, within a collective mindset, relatedness content coupled with salient self-modesty goals and assimilating procedures together support a sense of the commonness of one's success (e.g., "we are all able to do this"). In the case of failure when others have succeeded, a modesty goal and an assimilating procedure would render a distancing response irrelevant. Modesty goals and assimilating procedures do not make failure unimportant, but render the distancing response irrelevant, because successful others imply that success is possible (modesty) and putting distance between self and others is not the procedure that comes to mind (assimilation).

Cultural psychologists generally assume that societies differ in which mindset is socialized (Nisbett, 2003) and that only biculturals, having lived in more than one society, develop both mindsets (Hong, Morris, Chiu, \& Benet-Martinez, 2000). Following Schwartz (1992), we disagree with this formulation. To survive over time, societies must socialize members to be able to get along; to thrive, societies must socialize members to be able to choose their own way when resources allow. Thus, both individual success and relational harmony are pursued (albeit to varying degrees) and societies socialize for both individual and collective mindsets, though one or the other may be more commonly or more strongly cued (Oyserman, Kemmelmeier, \& Coon, 2002; Oyserman \& Lee, 2007, 2008a; Oyserman et al., 2009). Once learned, a mindset can be nonconsciously primed to influence culturally-relevant psychological processes and outcomes (e.g., social behaviors, values, beliefs, judgments, self-concept content, basic perceptual processes). These have been demonstrated with various primes such as describing oneself as similar to or different from friends and family, imagining oneself playing singles or doubles tennis, or simply circling singular or plural pronouns (for a meta-analytic review of experimental techniques and evidence, see Oyserman \& Lee, 2008b).

\section{Language as a prime of cultural mindset}

The fact that cultural mindsets can be readily primed by diverse contextual cues led us to hypothesize that language, an important cultural marker, could also be a potent mindset prime. Knowing a language is not just about knowing which words to use and how to put them together, but also knowing what to say in what context. Research on bilinguals has provided some evidence that language can prime mindset (for reviews, Chiu, Leung, \& Kwan, 2007; Oyserman \& Lee, 2007, 2008a). For example, bilinguals randomly assigned to use either one language (e.g., English) or another (e.g., Chinese) systematically differ in whether their recollections about autobiographical events (e.g., a birthday party) focus on themselves (what they were doing, thinking or feeling) or others in the context (who were there, what was happening; Marian \& Neis- ser, 2000). Moreover, bilinguals randomly assigned to use English tended to group objects on the basis of category membership, whereas those assigned to use Chinese grouped objects more on the basis of their relationships (Ji, Zhang, \& Nisbett, 2004).

In the current studies, we propose an expansion of the general idea that using different languages can prime different cultural mindsets. Because mindsets include content, process, and goals, we predict that language use should not only affect how positive self-descriptions are, but should also produce differences in relevant procedures and goals. Specifically, using a language that primes an individual mindset should trigger use of a contrasting procedure - contrasting oneself with others (cf. Kwan, John, Kenny, Bond, \& Robins, 2004) - and a self-enhancement goal with the behavioral consequence of distancing oneself from successful others when failure cannot be hidden (Tesser, 2000). Using a language that primes a collective mindset should trigger use of an assimilating procedure, relating and connecting oneself with others and a self-improvement or self-modesty goal with the behavioral consequence that one does not need to distance oneself from successful others when failure cannot be hidden.

This intuitive, perhaps even obvious, prediction has not been rigorously tested due to several limitations in prior research involving language. Studies typically conflate language and society, as can be seen by examining studies in Heine and Hamamura's (2007) comprehensive meta-analysis demonstrating cross-national differences in self-enhancing responses. Such conflation makes it impossible to tell if seemingly fixed, between-society differences were in fact primed by language. This shortcoming was addressed by Ross, Xun, and Wilson (2002) who randomly assigned Chinese-born students living in Canada to answer a questionnaire in English or Chinese, and found that those using English rather than Chinese wrote more positive self-descriptions and reported higher self-esteem. This finding is clearly relevant to the case we would like to make for language as a cultural mindset prime. However, because they assessed self-evaluations without inducing social comparison or failure, they did not address the larger question we raise about mindsets cuing content (positivity vs. modesty), process (contrasting and separating procedures vs. assimilating and connecting procedures) and goals (being better than others vs. fitting in with others). We address this question in the current studies.

With the exception of the research by Ross and colleagues (2002), the literature to date has not found a strong or consistent effect of experimentally manipulated language use on valueendorsements and self-descriptions. The overall effect of language in a recent meta-analysis of cultural mindset priming studies was small $(d=.10)$ and its confidence interval included both positive and negative effects (Oyserman \& Lee, 2008b). One possible reason for these mixed results is that studies differed in whether participant's attention was drawn to the language they were using in the context of the experiment. When participant's attention is drawn to language use, they are likely to attempt to correct for their understanding of the likely effects of language use on their responses. The assumption that people try to correct for likely effects of situational factors that their attention is drawn to is rooted in a large body of social cognition research. This research demonstrates first, that people are sensitive to subtle shifts in context, responding differently as context changes, and second, that when people are made aware of context, they attempt to correct for its effects but often overcorrect, resulting in the kind of variance in effects currently seen in the languagepriming literature (for reviews of correction and overcorrection effects, see Forster \& Liberman, 2007; Schwarz \& Clore, 2007; Wilson \& Brekke, 1994). To test the naturalistic effects of language as a subtle cue, its use has to be an unobtrusive feature in the experiment. 
The present research

We unobtrusively manipulated language and directly tested whether the language used shifts self-enhancement, turning it on or off. A language that primes an individual mindset (but not one that primes a collective mindset) should produce self-enhancing judgments and behaviors. We chose English and Chinese as our exemplar languages for two reasons: Meta-analytic results suggest that English-speaking peoples are more individualistic than others, even Western Europeans who speak other languages (Oyserman, Coon, \& Kemmelmeier, 2002). Moreover, Chinese culture is a good example of East-Asian collectivism, the most common contrast to Western individualism, and a regional root civilization whose language, traditions, and beliefs influenced neighboring countries such as Japan and Korea (Nisbett, Peng, Choi, \& Norenzayan, 2001; Stearns, Adas, Schwartz, \& Gilbert, 2004).

We conducted our studies in a Hong Kong university setting, where both English and Chinese are commonly used, allowing for unobtrusive manipulation of language and ecological validity. We varied social-comparison contexts across studies to increase the generalizability of findings, predicting that participants randomly assigned to use English (vs. Chinese) would make more selfenhancing social-comparative judgments (Studies 1 and 2) and show more social distancing after underperformance if not given an alternative way to protect their positive self-regard (Study 3 ).

English versions of materials are presented in this paper; Chinese versions are available from the first author. All predictions were directional, a priori, and evaluated with one-tailed significance tests (Rosenthal, Rosnow, \& Rubin, 2000).

\section{Study 1: better-than-average}

Self-enhancement, operationalized as the tendency to rate desirable traits as more self-defining and undesirable traits as more defining of the average student (Alicke, 1985; Taylor \& Brown, 1994), was hypothesized to be stronger when participants were randomly assigned to use English (vs. Chinese). We tested this hypothesis using ratings on traits from prior self-enhancement research, Confucian values, and the Ten Commandments. Following Alicke (1985), controllable and clearly desirable or undesirable traits were used to maximize the "better-than-average" effect.

\section{Methods}

\section{Participants and procedure}

Chinese University of Hong Kong (CUHK) students in two introductory psychology courses $(n=99,38$ men, age $M=19.25$, $S D=0.96$ ) participated in a class research exercise. In each course, one discussion section was randomly assigned to hear, read, and write in English, the other section to hear, read, and write in Chinese. Participants were unaware that sections differed in language used.

\section{Measures}

Participants rated 46 traits ("Rate the extent to which each trait describes you relative to the average CUHK student. This trait describes me... ( $1=$ much less than..., 5=about the same as..., $9=$ much more than...) the average CUHK student"; Alicke, 1985). About the same number of traits were desirable (24; e.g., considerate, knowing shame, revering seniors, honoring parents) as undesirable (22; e.g., phony, narrowly self-interested, envious, desiring your friend's partner). Ratings for undesirable traits were reverse-coded so that higher overall scores reflected greater selfenhancement (i.e., seeing desirable traits as more self-descriptive and undesirable traits as more others-descriptive).

\section{Analysis}

Preliminary analyses showed no gender-ratio, age, and trait-rating differences between courses (all $n s$ ), but found weak effects of gender and college-standing on trait-ratings. ${ }^{1}$ To control for these effects, we submitted the self-enhancement scores to a 2 (Language) $\times 2$ (Desirability) mixed ANCOVA, with Language as a between-participants factor, Desirability as a within-participants factor, gender and college-standing as covariates.

\section{Results and discussion}

As predicted, language condition influenced self-enhancement. Participants randomly assigned to use English $(M=5.65$, $S D=0.65)$ reported significantly more self-enhancement than participants randomly assigned to use Chinese $(M=5.44, S D=0.78)$, $F(1,95)=3.55, p=.03, d=0.29$. Effects were consistent across desirable and undesirable traits (Language $\times$ Desirability $F=0.93$, $n s$; see Table 1 and Fig. 1) and went beyond the general tendency to rate desirable traits as self-descriptive (tested against scale-midpoint, English $t(51)=10.94, p<.001$; Chinese $t(46)=7.23, p<.001$ ). The tendency to rate undesirable traits as others-descriptive was evident among participants randomly assigned to use English $(t(51)=3.31, p=.001)$, but not among those randomly assigned to use Chinese $(t(46)=0.74, n s)$. These effects were not moderated by gender $(F s<.02, n s)$ or cultural indigenousness of traits (Confucian vs. non-Confucian; $F s<1.48, n s$ ).

Results suggest that unobtrusive shift in language influenced self-enhancement, with similar effect sizes whether traits were desirable or undesirable, culturally indigenous or non-indigenous. Using a standardized set of traits had the advantage that all participants rated themselves on the same traits, but the disadvantage that participants might not have found all traits particularly selfrelevant. To address this limitation, Study 2 adopted an idiographic approach (Allport, 1962), first having participants describe a moral success or failure of their own, then asking them whether others would have behaved as they had.

\section{Study 2: "holier-than-thou"}

Self-enhancement, operationalized as the tendency to see one's moral successes as unique and moral failures as common (Suls \& Wan, 1987), was hypothesized to be stronger among participants randomly assigned to use English (vs. Chinese). We tested this hypothesis by asking participants to think of a time when they resisted (or succumbed to) temptation, write about it, then rate how unique or common their response to temptation was.

\section{Methods}

\section{Participants and procedure}

CUHK introductory psychology students ( $n=76,25$ men, age $M=19.16, S D=0.87$ ) participated. Language was manipulated as in Study 1. In each section, students were randomly assigned to write about a moral success or a moral failure: "Recall an incident in your life where you struggled to do the right thing and eventually stood firm and succeeded in doing the right thing (or gave in and failed to do the right thing)... . Focus on your feelings and emotions while experiencing the struggle and success (or failure)." Participants wrote for $5 \mathrm{~min}$, then rated the uniqueness of their response.

\footnotetext{
1 Women scored higher on desirable, $F(1,94)=5.18, p=.03$, but not undesirable traits, $F(1,94)=1.09, p=.30$. Seniors scored higher on undesirable, $b=.28$, $t(94)=1.91, p=.06$, but not desirable traits, $b=-.04, t(94)=-0.42, p=.68$.
} 
Table 1

Self-enhancement (Studies 1 and 2) and social distancing (Study 3): Cell sizes, means, and standard deviations by mindset prime and condition.

\begin{tabular}{|c|c|c|c|c|c|c|c|c|c|}
\hline \multirow[t]{3}{*}{ Study } & \multirow[t]{3}{*}{ Dependent variable } & \multirow[t]{3}{*}{ Condition } & \multicolumn{7}{|c|}{ Mindset prime } \\
\hline & & & \multicolumn{3}{|c|}{ English } & \multicolumn{3}{|c|}{ Chinese } & \multirow[b]{2}{*}{$d$} \\
\hline & & & $n$ & $M$ & $S D$ & $n$ & $M$ & $S D$ & \\
\hline \multirow[t]{2}{*}{ Study 1} & Self-enhancement score & Desirable traits & 52 & 5.91 & 0.60 & 47 & 5.77 & 0.73 & 0.21 \\
\hline & & Undesirable traits $^{\mathrm{a}}$ & & 5.39 & 0.85 & & 5.11 & 1.02 & 0.30 \\
\hline \multirow[t]{2}{*}{ Study 2} & Self-enhancement score & Moral success ${ }^{\mathrm{b}}$ & 17 & 6.65 & 1.73 & 20 & 5.60 & 1.57 & 0.64 \\
\hline & & Moral failure & 17 & 5.71 & 1.45 & 22 & 5.09 & 1.41 & 0.43 \\
\hline \multirow[t]{2}{*}{ Study 3} & Felt closeness to outperforming peers & Not self-affirmed & 47 & 3.47 & 1.69 & 38 & 5.11 & 1.87 & 0.92 \\
\hline & & Self-affirmed & 45 & 4.27 & 1.66 & 44 & 4.55 & 1.84 & 0.16 \\
\hline
\end{tabular}

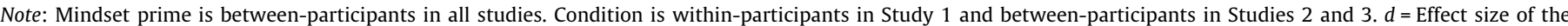
mindset prime.

a The scale was "This trait describes me ... (1 = much less than . .., $5=$ about the same as..., 9= much more than ...) the average CUHK student." Ratings were reverse-coded for

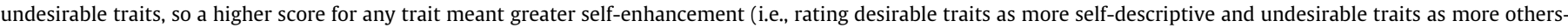
descriptive).

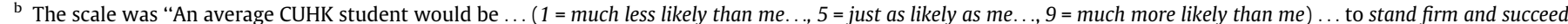

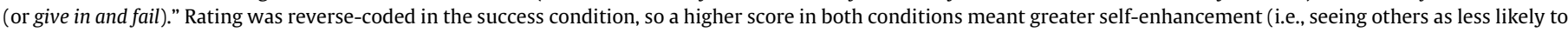
resist temptation or more likely to succumb to temptation).

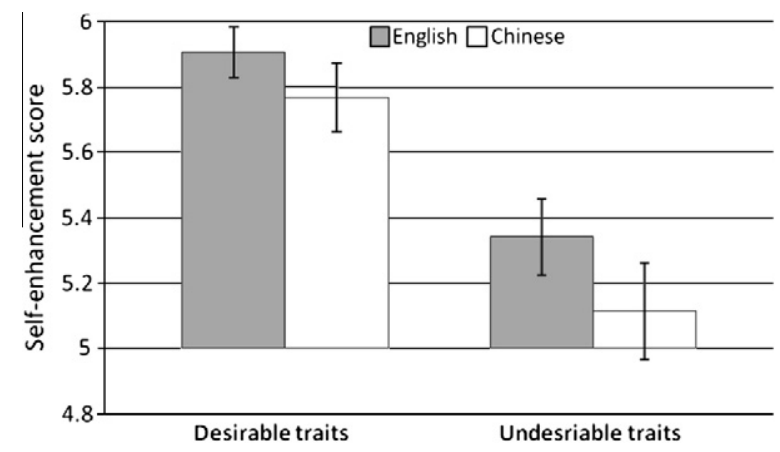

Fig. 1. Study 1: Self-enhancement (seeing desirable traits as more self-descriptive and undesirable traits as more others-descriptive) as a function of mindset prime and trait desirability. Note: Error bar represents standard error of the mean. Higher self-enhancement scores reflect higher agreement that desirable traits are selfdescriptive and lower agreement that undesirable traits are self-descriptive.

\section{Measures}

Participants were asked "How well do you think an average CUHK student would do in the same situation you described above?", and responded on a 9-point scale: "An average CUHK student would be... (1 = much less likely than me..., 5 = just as likely as me..., $9=$ much more likely than me) ...to stand firm and succeed (or give in and fail)". Rating was reverse-coded in the success condition so that higher scores reflected greater self-enhancement (i.e., others are either less likely to resist temptation or more likely to succumb to temptation).

\section{Analysis}

Preliminary analyses showed no effect of gender or collegestanding, so neither variable was included in analyses. Selfenhancement scores were submitted to a 2 (Language) $\times 2$ (Morality) between-participants ANOVA.

\section{Results and discussion}

As predicted, language condition influenced self-enhancement. Participants randomly assigned to use English $(M=6.18$, $S D=1.64$ ) reported significantly more self-enhancement than participants randomly assigned to use Chinese $(M=5.33, S D=1.49)$, $F(1,72)=5.49, p=.01, d=0.54$. Effects were consistent across moral success and failure (Language $\times$ Morality $F=0.37$, ns; see Table 1 and Fig. 2) and went beyond the general tendency to perceive one's

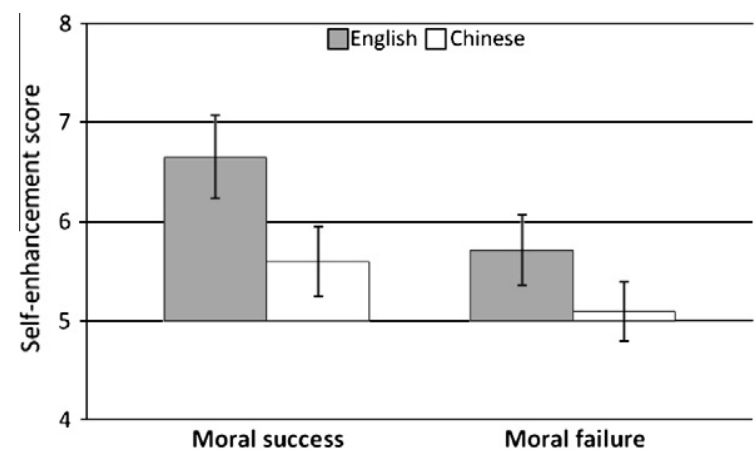

Fig. 2. Study 2: Self-enhancement (seeing others are less likely to resist temptation or more likely to succumb to temptation) as a function of mindset prime and moral success or failure condition. Note: Error bar represents standard error of the mean. Higher self-enhancement scores reflect higher agreement that a recalled moral success is unique and lower agreement that a recalled moral failure is unique.

moral successes as unique (tested against scale-midpoint, English $t(16)=3.93, p<.001$; Chinese $t(19)=1.71, p=.05)$. The general tendency to perceive one's moral failures as common was evident among participants randomly assigned to use English $(t(16)=2.02$, $p=.03)$, but not among those randomly assigned to use Chinese $(t(21)=0.30, n s)$. These effects were not driven by different moral experience in participants' stories, as content-analysis revealed no differences across conditions in their thematic content (most commonly, academic situations) or in whether their emotional experience was interpersonally engaged (e.g., respectful) or disengaged (e.g., proud; Kitayama, Markus, \& Kurokawa, 2000).

Studies 1 and 2 demonstrate that language can be a cultural mindset prime that amplifies or diminishes self-enhancement in social comparisons. Both studies suggest that previously found cross-national differences in self-enhancement can be attributed at least in part to the salient cultural mindsets primed by the language used in context. In Study 3, we continued to focus on personally important experience by capitalizing on the most common theme in participants' idiographic accounts, their academic performance. To reduce heterogeneity and increase vividness, we standardized the situation and focused on performance in situ (rather than recall and judgment, as in Studies 1 and 2).

Study 3 extended beyond Studies 1 and 2 in several other respects as well. First, in Studies 1 and 2, participants could simply rate themselves as better than others without ever thinking about what reality was and whether they truly were better. Study 3 
removed this option by giving participants clear feedback that they had performed worse than others, and tested whether this prompted social distancing. Second, Studies 1 and 2 demonstrated self-enhancing outcomes, but were not tests of process. Study 3 used a moderation-of-process design (Spencer, Zanna, \& Fong, 2005). Half of participants (but not the other half) were given an opportunity to buttress their self-worth, a procedure that should remove the need to protect self-worth through social distancing. Third, to demonstrate the breadth of cultural mindset priming effects, Study 3 sought to replicate prior findings that language can prime individual-focused vs. relation-focused self-descriptions (Kemmelmeier \& Cheng, 2004; Ross et al., 2002; Trafimow, Silverman, Fan, \& Law, 1997).

\section{Study 3: negative social comparison and self-affirmation}

Self-enhancing behavior, operationalized as the tendency to distance oneself from outperforming others (Tesser, 2000), was hypothesized to be stronger among participants randomly assigned to use English (vs. Chinese). But if self-worth was buffered, no distancing would be expected. We tested this hypothesis by giving participants failure feedback that set up a clear negative contrast with other participants. Half of the participants were given a chance to buffer self-worth through a self-affirmation manipulation, half were not.

Unfavorable social comparison (discovering that one performed worse than others) in an important domain is widely used to study self-enhancement, because it undermines the ability to perceive oneself as positively distinct (Tesser, 2000). If self-worth is based in part on positive contrast from others, an unfavorable comparison should threaten self-worth and instigate attempts to regain it. One way to regain self-worth is to make the unfavorable comparison less salient, so people distance themselves from clearly outperforming others (Tesser, Crepaz, Collins, Cornell, \& Beach, 2000)-unless self-worth is protected through other means such as affirming core values (for reviews, see Sherman \& Cohen, 2006; Steele, 1988).

\section{Methods}

\section{Participants and procedure}

CUHK students ( $n=174,68$ men, age $M=20.60, S D=1.44)$ participated in groups of $12-20$ in a computer lab. Each was seated individually. Language manipulation followed Studies 1 and 2, with an added manipulation check of language effects on salient self-concept content. Participants wrote 20 self-descriptive statements (Kuhn \& McPartland, 1954), and then were randomly assigned to one of two self-affirmation conditions (self-affirmed, control). Self-affirmed participants completed Tesser and colleague's (2000) value-ranking task ${ }^{2}$ before proceeding to the threatening math test. Control participants proceeded directly to the math test.

The test was described as having been validated by the School of Education and predictive of reasoning ability and course grades. It included six difficult math questions pre-tested to feel solvable with sufficient time. However, participants did not have sufficient time. We gave participants only 15 s per question, creating uncertainty about answers because their computations were only nearly complete when they had to respond. After the test, participants waited $5 \mathrm{~s}$ while the computer appeared to be processing answers and creating statistics. They then received the bogus feedback,

\footnotetext{
2 Participants ranked 18 values (e.g., an exciting life, a world at peace) in order of personal importance, then detailed their rationale for choosing one important value (the one they ranked fifth).
}

"Your number of correct answers is 2 out of 6 . The average number of correct answers among participants who have completed the test so far in this classroom is 3.7 out of $6 . "$

\section{Measures}

Participants reported how close they felt to the other students taking the test ( $1=$ not close at all, $9=$ very close $)$ and as a comparison, to their friends in general. As manipulation checks, they also reported how they performed relative to other students $(1=$ much worse, $9=$ much better) and how they felt after completing the test (1 = bad, 9 = good $)$.

\section{Manipulation checks}

Content-coding of self-descriptions (Trafimow, Triandis, \& Goto, 1991) confirmed more individual-trait content in English (89\%) than in Chinese (84\%), more relational-collective content in Chinese $(16 \%)$ than in English $(11 \%), t(171)=2.49, p=.01, d=0.38$.

The failure feedback was effective: all participants reported performing worse than others $(M=3.20, S D=1.16)$ and feeling bad $(M=2.86, S D=1.61)$. Both means were significantly below the scale-midpoint, $t(173) \mathrm{s}=17.47$ and 20.49, $p s<.001$.

\section{Analysis}

Preliminary analyses showed no effect of gender or collegestanding, so neither variable was included in analyses. The two closeness scores (to other students taking the test and to friends) were submitted to a 2 (Language) $\times 2$ (Self-Affirmation) $\times 2$ (Target) mixed ANOVA. Language and Self-Affirmation were between-participants; Target was within-participants.

\section{Results and discussion}

As predicted, language condition influenced concern about selfworth. Participants randomly assigned to use English felt more distant from their outperforming peers than did participants randomly assigned to use Chinese, $F(1,170)=18.17, p<.001$. Language condition had a sizeable effect when self-worth was at stake $(d=0.92)$, but its effect was completely eliminated when self-worth was protected by affirmation, $F(1,170)=0.56$, $n$ s (see Table 1 and Fig. 3 left-panel), yielding a significant Language $\times$ Self-Affirmation interaction, $F(1,170)=6.43, p=.01$. Self-affirmation significantly reduced the social distancing response of participants randomly assigned to use English $(F=4.73, p=.02, d=0.48)$, but had no significant effect on participants randomly assigned to use Chinese $(F=2.06, n s)$.

No matter which language or affirmation condition they were assigned to, participants always reported feeling close to friends (Ms. from 6.18 to 6.39; main and interaction effects $F s<0.24$, ns; Fig. 3 right-panel). Thus, the social distancing response specifically targeted outperforming peers (who posed a threat to one's selfworth), but not friends (who posed no such threat); in contrast, how close participants felt to outperforming peers was dependent on language and self-affirmation conditions, yielding the predicted Language $\times$ Self-Affirmation $\times$ Target interaction $(F(1,170)=3.97$, $p=.02$; see Fig. 3 ).

\section{General discussion}

Three studies support our hypothesis that language can function as a cultural mindset prime, turning on or off the tendency to positively contrast oneself from others when making social comparison-based judgments (Studies 1 and 2) and to distance oneself from outperforming others unless self-worth has been protected (Study 3). Our results demonstrate that language has a causal impact on judgment and behavior when it is an unobtrusive feature of 

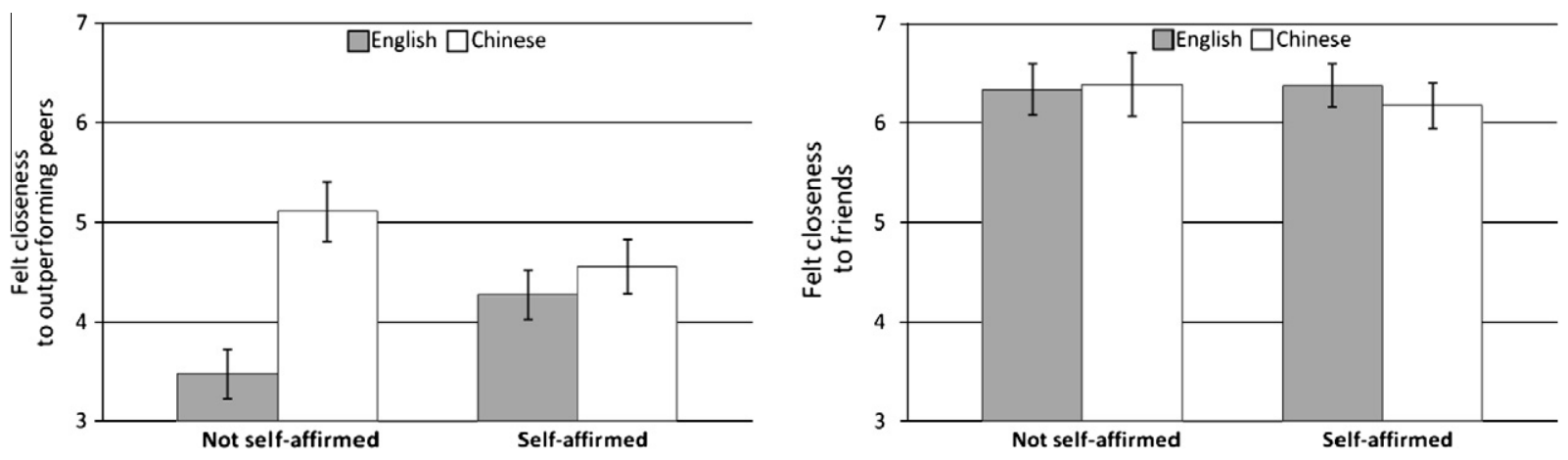

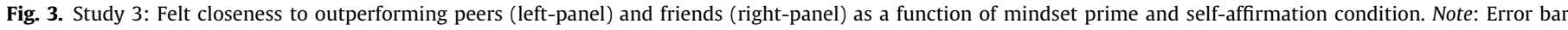
represents standard error of the mean.

the immediate context and primes cultural mindset. Effect sizes range from small $(d=0.29)$, to moderate $(d=0.54)$, to large $(d=0.92)$, increasing as dependent variables became more personally relevant and the experimental context became more vivid; the largest effects were found when an actual social comparison was instantiated in an important domain (academic performance). Our findings clearly go beyond prior research (Ross et al., 2002) by demonstrating effects of language use in social-comparison situations. Our results also shed light on the previously unexplored issue of the contingencies of cultural mindset priming effects (see Oyserman \& Lee, 2008b), suggesting that subjectively important outcomes, rather than being unsusceptible to contextual influence, are strongly affected by contextual cues that prime cultural mindsets.

Prior research has found that when content and procedure are both primed, they can have multiplicative effects (e.g., on perceptual readiness; Forster \& Liberman, 2007). This notion has two implications for cultural mindset effects on self-enhancement. First, effects should be more pronounced when all aspects of the individual mindset (content, procedure, and goal) are salient and relevant to the situation, as they were in Study 3, which showed the largest effects. Second, effects should be more pronounced in contexts that focus on comparisons because contrasting and assimilating procedures are inherent in comparisons, but not necessarily relevant in contexts that do not involve comparisons. Future research using language and other cultural mindset primes may well find that priming an individual mindset increases self-enhancement particularly when framed in comparative terms that involve contrasting procedures (e.g., "better-than-average", Alicke, 1985; "better-than-I-was-before", Wilson \& Ross, 2001). When selfenhancement does not explicitly involve a contrasting procedure (e.g., taking more responsibility for success than failure, Blaine \& Crocker, 1993; skepticism about unflattering feedback, Ditto \& Lopez, 1992), cultural mindset priming effects may be weaker.

Whether self-enhancement is a culturally contingent phenomenon (Heine \& Buchtel, 2009; Heine \& Hamamura, 2007; Heine et al., 2007a, 2007b) or a pancultural phenomenon (Sedikides et al., 2003, 2005, 2007a, 2007b) is hotly debated. But neither perspective appears to predict our findings. Heine and colleagues argue that self-enhancement is a uniquely Western phenomenon, unobservable among East Asians. Our studies document selfenhancing judgments and behaviors among people in Hong Kong. More importantly, within this single cultural group, self-enhancing tendencies vary as a function of which cultural mindset is salient at the moment of judgment. Such variability is not predicted by the culturally contingent perspective, which assumes a cultural group to be either self-enhancing or not self-enhancing.

Sedikides and colleagues argue from a pancultural viewpoint that people in all cultures self-enhance, but do so by focusing on different domains. Independent people self-enhance on individualistic attributes; interdependent people self-enhance on collectivistic attributes. Cultural mindset priming effects are also not predicted in this account. Our findings suggest that even people socialized in collectivistic contexts can self-enhance when an individual mindset is primed and that self-enhancement is not limited to collectivistic attributes. Across three studies, language functions as a cultural mindset prime and shifts people's tendencies to selfenhance across a variety of tasks. Study 1 also shows that cultural mindset priming affects endorsement of culturally indigenous, Confucianism-based, more collectivistic traits as well as non-indigenous, more individualistic traits. Therefore, cultural mindset priming can promote self-enhancement in general, rather than self-enhancement on a particular kind of attributes.

As a corollary, we would predict similar mindset priming effects even among Americans. For example, after circling singular pronouns $(I, m e)$ rather than plural pronouns (we,us), Americans should show a stronger tendency to self-enhance on both individualistic and collectivistic attributes. While we used language as a naturalistic prime, an important next step will be to demonstrate the same effects for "Westerners," whose chronic tendency to self-enhance should be curtailed when a collective mindset is salient. A limitation of using naturalistic primes such as language is that it is difficult to parse the specific process cued. Other less naturalistic primes such as thinking about differences from vs. similarities to family and friends (Trafimow et al., 1991), circling singular vs. plural pronouns (Brewer \& Gardner, 1996; Gardner, Gabriel, \& Lee, 1999) or seeing posters promoting individual vs. group pursuits (Zhu \& Meyers-Levy, 2009) can be useful in specifying the process by testing "active ingredients" in naturalistic primes.

That said, our results provide an important first step by demonstrating that self-enhancement can be easily turned on and off by priming cultural mindsets. Our results also raise the possibility of reframing the universal vs. culturally contingent debate: rather than conceptualizing self-enhancement as either universal or contingent, or as either about individualistic content or about collectivistic content, a more fruitful question to address is, "In which contexts is self-enhancement activated?" This reframing within cultural psychology represents a paradigm shift that resembles the Nature-Nurture debate and its new focus. Genetic effects are now known to manifest only when triggered by environmental factors, so the same gene pool can produce different phenotypes in different environments (e.g., Mischel, Champagne, Meaney, \& Sokolowski, 2009). Phenotypes result from neither nature alone nor nurture alone. Likewise, self-enhancement is not either universal or contingent. It is both universal (in that it is observable across societies) and contingent (in that it is observed only in the right contexts and activated by the right cues, whose relative 
prominence differs by culture; see also Norenzayan \& Heine, 2005) Contexts and cues are what produce cultural differences in selfenhancement. They hold promise of becoming the new paradigm of theorizing and research in cultural psychology.

\section{Acknowledgments}

We gratefully acknowledge support by Direct Grant 2020855 from the Chinese University of Hong Kong to Lee and Bond. We also thank Kelly Y. L. Ku and Alan C. N. Wong for their generous support to data collection.

\section{References}

Alicke, M. D. (1985). Global self-evaluation as determined by the desirability and controllability of trait adjectives. Journal of Personality and Social Psychology, 49, 1621-1630.

Allport, G. D. (1962). The general and the unique in psychological science. Journal of Personality, 30, 405-422.

Blaine, B., \& Crocker, J. (1993). Self-esteem and self-serving biases in reactions to positive and negative events: An integrative review. In R. F. Baumeister (Ed.) Self-esteem: The puzzle of low self-regard (pp. 55-85). New York: Plenum.

Brewer, M. B., \& Gardner, W. L. (1996). Who is this "we"? Levels of collective identity and self-representations. Journal of Personality and Social Psychology, 71, 83-93.

Chiu, C.-y., Leung, A. K.-y., \& Kwan, L. (2007). Language, cognition, and culture: Beyond the Whorfian hypothesis. In S. Kitayama \& D. Cohen (Eds.), Handbook of cultural psychology (pp. 668-688). New York: Guilford.

Ditto, P. H., \& Lopez, D. F. (1992). Motivated skepticism: Use of differential decision criteria for preferred and nonpreferred conclusions. Journal of Personality and Social Psychology, 63, 568-584.

Forster, J., \& Liberman, N. (2007). Knowledge activation. In A. W. Kruglanski \& E. T. Higgins (Eds.), Social psychology: Handbook of basic principles (2nd ed., pp. 201-231). New York: Guilford.

Gardner, W. L., Gabriel, S., \& Lee, A. Y. (1999). "I" value freedom, but "we" value relationships: Self-construal priming mirrors cultural differences in judgment Psychological Science, 10, 321-326.

Heine, S. J., \& Buchtel, E. E. (2009). Personality: The universal and culturally specific Annual Review of Psychology, 60, 369-394.

Heine, S. J., \& Hamamura, T. (2007). In search of East Asian self-enhancement Personality and Social Psychology Review, 11, 1-24

Heine, S. J., Kitayama, S., \& Hamamura, T. (2007a). Inclusion of additional studies yields different conclusions: Comment on Sedikides, Gaertner, \& Vevea (2005) Journal of Personality and Social Psychology. Asian Journal of Social Psychology, $10,49-58$.

Heine, S. J., Kitayama, S., \& Hamamura, T. (2007b). Which studies test whether self enhancement is pancultural? Reply to Sedikides, Gaertner, and Vevea, 2007. Asian Journal of Social Psychology, 10, 198-200.

Hofstede, G. (1980). Culture's consequences: International differences in work-related values. Beverly Hills, CA: Sage.

Hong, Y.-y., Morris, M. W., Chiu, C.-y., \& Benet-Martinez, V. (2000). Multicultural minds: A dynamic constructivist approach to culture and cognition. American Psychologist, 55, 709-720.

Ji, L.-J., Zhang, Z., \& Nisbett, R. E. (2004). Is it culture or is it language? Examination of language effects in cross-cultural research on categorization. Journal of Personality and Social Psychology, 87, 57-65.

Kim, U., Triandis, H. C., Kagitcibasi, C., Choi, S.-C., \& Yoon, G. (Eds.). (1994). Individualism and collectivism: Theory, method, and applications. Thousand Oaks, CA: Sage.

Kemmelmeier, M., \& Cheng, B. (2004). Language and self-construal priming: A replication and extension in a Hong Kong sample. Journal of Cross-Cultural Psychology, 35, 705-712.

Kitayama, S., Markus, H. R., \& Kurokawa, M. (2000). Culture, emotion, and wellbeing: Good feelings in Japan and the United States. Cognition and Emotion, 14 93-124.

Kuhn, M. H., \& McPartland, T. S. (1954). An empirical investigation of self-attitudes. American Sociological Review, 19, 68-76.

Kwan, V. S. Y., John, O. P., Kenny, D. A., Bond, M. H., \& Robins, R. W. (2004). Reconceptualizing individual differences in self-enhancement bias: An interpersonal approach. Psychological Review, 111, 94-110.

Leary, M. R. (2007). Motivational and emotional aspects of the self. Annual Review of Psychology, 58, 317-344.

Marian, V., \& Neisser, U. (2000). Language-dependent recall of autobiographical memories. Journal of Experimental Psychology: General, 129, 361-368.

Markus, H. R., \& Kitayama, S. (1991). Culture and the self: Implications for cognition, emotion, and motivation. Psychological Review, 98, 224-253.

Mischel, W., Champagne, F., Meaney, M., \& Sokolowski, M. (2009). The new genetics and what it means for psychological science. Presidential symposium at the annual convention of the Association for Psychological Science, San Francisco, CA.
Nisbett, R. E. (2003). The geography of thought: How Asians and Westerners think differently... and why. New York: Free Press.

Nisbett, R. E., Peng, K., Choi, I., \& Norenzayan, A. (2001). Culture and systems of thought: Holistic vs. analytic cognition. Psychological Review, 108, 291-310.

Norenzayan, A., \& Heine, S. J. (2005). Psychological universals: What are they and how can we know? Psychological Bulletin, 135, 763-784.

Oyserman, D., Coon, H. M., \& Kemmelmeier, M. (2002). Rethinking individualism and collectivism: Evaluation of theoretical assumptions and meta-analyses. Psychological Bulletin, 128, 3-72.

Oyserman, D., Kemmelmeier, M., \& Coon, H. M. (2002). Cultural psychology, a new look: Reply to Bond (2002), Fiske (2002), Kitayama (2002), and Miller (2002). Psychological Bulletin, 128, 110-117.

Oyserman, D., \& Lee, S. W. S. (2007). Priming 'culture': Culture as situated cognition. In S. Kitayama \& D. Cohen (Eds.), Handbook of cultural psychology (pp. 255-279). New York: Guilford.

Oyserman, D., \& Lee, S. W. S. (2008a). A situated cognition perspective on culture: Effects of priming cultural syndromes on cognition and motivation. In R. M. Sorrentino \& S. Yamaguchi (Eds.), Handbook of motivation and cognition across cultures (pp. 237-265). San Diego, CA: Elsevier.

Oyserman, D., \& Lee, S. W. S. (2008b). Does culture influence what and how we think? Effects of priming individualism and collectivism. Psychological Bulletin, $134,311-342$

Oyserman, D., Sorensen, N., Reber, R., \& Chen, S. X. (2009). Connecting and separating mind-sets: Culture as situated cognition. Journal of Personality and Social Psychology, 97, 217-235.

Rosenthal, R., Rosnow, R. L., \& Rubin, D. B. (2000). Contrasts and effect sizes in behavioral research: A correlational approach. New York: Cambridge University Press.

Ross, M., Xun, E. W. Q., \& Wilson, A. E. (2002). Language and the bicultural self. Personality and Social Psychology Bulletin, 28, 1040-1050.

Schwartz, S. H. (1992). Universals in the content and structure of values: Theoretical advances and empirical tests in 20 countries. In M. P. Zanna (Ed.). Advances in experimental social psychology (Vol. 25, pp. 1-65). New York: Academic Press.

Schwarz, N., \& Clore, G. L. (2007). Feelings and phenomenal experiences. In A. W. Kruglanski \& E. T. Higgins (Eds.), Social psychology: Handbook of basic principles (2nd ed., pp. 385-407). New York: Guilford.

Sedikides, C., Gaertner, L., \& Toguchi, Y. (2003). Pancultural self-enhancement. Journal of Personality and Social Psychology, 84, 60-79.

Sedikides, C., Gaertner, L., \& Vevea, J. L. (2005). Pancultural self-enhancement reloaded: A meta-analytic reply to Heine (2005). Journal of Personality and Social Psychology, 89, 539-551.

Sedikides, C., Gaertner, L., \& Vevea, J. L. (2007a). Inclusion of theory-relevant moderators yield the same conclusions as Sedikides, Gaertner, and Vevea (2005): A meta-analytical reply to Heine, Kitayama, and Hamamura (2007). Asian Journal of Social Psychology, 10, 59-67.

Sedikides, C., Gaertner, L., \& Vevea, J. L. (2007b). Evaluating the evidence for pancultural self-enhancement. Asian Journal of Social Psychology, 10, 201-203.

Sherman, D. K., \& Cohen, G. L. (2006). The psychology of self-defense: Selfaffirmation theory. Advances in Experimental Social Psychology, 38, 183-242.

Spencer, S. J., Zanna, M. P., \& Fong, G. T. (2005). Establishing a causal chain: Why experiments are often more effective in examining psychological process than meditational analyses? Journal of Personality and Social Psychology, 89, 845-851.

Stearns, P. N., Adas, M., Schwartz, S. B., \& Gilbert, M. J. (2004). World civilizations: The global experience (4th ed.). Upper Saddle River, NJ: Prentice Hall.

Steele, C. M. (1988). The psychology of self-affirmation: Sustaining the integrity of the self. In L. Berkowitz (Ed.). Advances in experimental social psychology (Vol. 21, pp. 261-302). San Diego, CA: Academic Press.

Suls, J., \& Wan, C. K. (1987). In search of the false-uniqueness phenomenon: Fear and estimates of social consensus. Journal of Personality and Social Psychology, $52,211-217$

Taylor, S. E., \& Brown, J. D. (1994). Positive illusions and well-being revisited: Separating fact from fiction. Psychological Bulletin, 116, 21-27.

Tesser, A. (2000). On the confluence of self-esteem maintenance mechanisms. Personality and Social Psychology Review, 4, 290-299.

Tesser, A., Crepaz, N., Collins, J. C., Cornell, D., \& Beach, S. R. H. (2000). Confluence of self-esteem regulation mechanisms: On integrating the self-zoo. Personality and Social Psychology Bulletin, 26, 1476-1489.

Trafimow, D. Silverman, E. S., Fan, R. M.-T, \& Law, J. S. F. (1997). The effects of language and priming on the relative accessibility of the private self and the collective self. Journal of Cross-Cultural Psychology, 28, 109-123.

Trafimow, D., Triandis, H., \& Goto, S. (1991). Some tests of the distinction between the private self and the collective self. Journal of Personality and Social Psychology, 60, 649-655.

Triandis, H. C. (1995). Individualism and collectivism. Boulder, CO: Westview.

Wilson, T. D., \& Brekke, N. (1994). Mental contamination and mental correction: Unwanted influences on judgments and evaluations. Psychological Bulletin, 116, $117-142$.

Wilson, A. E., \& Ross, M. (2001). From chump to champ: People's appraisals of their earlier and present selves. Journal of Personality and Social Psychology, 80, 572-584.

Zhu, J. R., \& Meyers-Levy, J. (2009). The influence of self-view on context effects: How display fixtures can affect product evaluations? Journal of Marketing Research, 46, 37-45. 